\title{
TECENDO CONHECIMENTOS DE MULTIPLICAÇÃO COM O USO DA PLATAFORMA KHAN ACADEMY COM ALUNOS DO 5' ANO DO ENSINO FUNDAMENTAL
}

\author{
WEAVING KNOWLEDGE OF MULTIPLICATION WITH THE USE OF THE KHAN \\ ACADEMY PLATFORM WITH STUDENTS OF THE 5th YEAR OF \\ FUNDAMENTAL EDUCATION
}

Itaciara da Costa de Vasconcelos ${ }^{1}$

ORCID iD: 0000-0001-7697-5523

Alexandra Nascimento de Andrade 2

ORCID iD: $\underline{0000-0002-9525-4585}$

Felipe da Costa Negrão ${ }^{3}$

ORCID iD: $\underline{0000-0001-6840-6670}$

\section{RESUMO}

O presente artigo tem o objetivo de apresentar as contribuições do uso da plataforma Khan Academy nas aulas de Matemática, com alunos do $5^{\circ}$ ano, do Ensino Fundamental de uma Escola Municipal, da Zona Leste, da cidade de Manaus (AM). O uso de recursos tecnológicos no Ensino de Matemática converge para a superação de estigmas e concepções enraizadas de que esse componente curricular é cansativo, decorativo e sem contextualização. Por isso, desenvolveu-se uma pesquisa-ação interventiva, na qual organizamos uma Sequência Didática com atividades que envolveu a operação de multiplicação e o uso da plataforma Khan Academy, isto a fim de oportunizar uma experiência de aprendizado significativo. Nesse ínterim, os registros da sequência didática foram coletados a partir de conversas informais, observações, registros no caderno de campo e filmagens das ações docentes e discentes frente a proposta de trabalho com o Khan Academy. Os resultados da ação demonstram o aumento do interesse dos estudantes, que outrora se mantinham dispersos nas aulas de matemática, além de possuírem notas abaixo da média na disciplina. Sendo assim, consideramos que o uso desta plataforma no processo de ensino e aprendizagem da matemática, quando explorada de modo planejado, pode ser uma forte aliada a didática do professor.

Palavras-chave: Multiplicação. Khan Academy. Matemática. Gamificação.

\footnotetext{
${ }^{1}$ Especialista em Gestão, Orientação e Supervisão Escolar pelo Centro Universitário do Norte (UNINORTE) e em Letramento Digital pela Universidade do Estado do Amazonas (UEA), Professora (Semed-Am), Manaus, Amazonas, Brasil. Endereço: Rua Dorval Porto, 88, Conjunto Villa Real, Cidade Nova, Manaus, Amazonas, Brasil; CEP: 60097-154. E-mail: itaciara_brasil23@ hotmail.com

${ }^{2}$ Mestre em Educação em Ciências na Amazônia pela Universidade do Estado do Amazonas (UEA). Pedagoga (Seduc - Am), Manaus, Amazonas, Brasil. Endereço para correspondência: Rua Argonalta, 252, Distrito Industrial 2, Manaus, Amazonas, Brasil, CEP: 69007-057. E-mail: alexandra_deandrade@ hotmail.com

${ }^{3}$ Mestre em Educação em Ciências na Amazônia pela Universidade do Estado do Amazonas (UEA). Professor do Departamento de Métodos e Técnicas da Universidade Federal do Amazonas (UFAM), Manaus, Amazonas, Brasil. Endereço para correspondência: Rua Coreau, 10, Qd 64, São José Operário, Manaus, Amazonas, Brasil, CEP: 69086-161. E-mail: felipe.unl@ hotmail.com
} 


\begin{abstract}
This paper is about the contributions of the use of the Khan Academy platform in Mathematics classes, with 5th grade students, from the Elementary School of a Municipal School, which is located in the East Zone, in the city of Manaus-Am. The use of technological resources in Mathematics Education converges to overcome stigmas and entrenched conceptions that this curricular component is tiring, decorative and without contextualization. For this reason, an interventional action research was developed, in which we organized a Didactic Sequence with activities that involved the multiplication operation and the use of the Khan Academy platform, in order to provide a meaningful learning experience. In the meantime, the records of the didactic sequence were collected from informal conversations, observations, records in the field notebook and footage of the teaching and student actions in view of the work proposal with Khan Academy. The results of the action demonstrate an increase in the interest of students, who were once dispersed in mathematics classes, in addition to having belowaverage grades in the discipline. Therefore, we consider that the use of this platform in the process of teaching and learning mathematics, when explored in a planned way, can be a strong ally to the didactics of the teacher.
\end{abstract}

Keywords: Multiplication. Khan Academy. Mathematics. Gamification.

\title{
1 INTRODUÇÃO
}

A internet faz parte do cotidiano dos alunos do século XXI, uma vez que as demandas sociais exigem o conhecimento e o uso de recursos tecnológicos e comunicacionais. Nesse sentido, é comum que estudantes da Educação Básica tenham acesso ao universo dela, inclusive, atualmente, devido ao cenário de pandemia em que muitas atividades acadêmicas e laborais estão sendo realizadas por meio das mídias. Este cenário afeta e modifica nossos hábitos, modos de trabalhar e de aprender (DINIZ, 2001), introduzindo novas necessidades frente às tecnologias digitais de informação e comunicação (TDIC).

Uma nova era na Educação! Um mundo novo se abre em acelerado processo de globalização; é uma sociedade espantosamente dinâmica, instável e evolutiva, onde o elemento fundamental e decisivo é a mudança de paradigmas (DINIZ, 2001. p. 1).

Prensky (2001) aduz que os alunos de hoje são nativos digitais, pois crescem rodeados de tecnologias, manuseando ferramentas e plataformas com muita facilidade; com isso processam informações de modo distinto das gerações anteriores. Por seu turno, nesse cenário, o desafio da escola e dos professores é adaptar-se a esse "novo" contexto, assumindo uma postura investigativa, ou seja, a fim de serem reconhecidos como imigrantes digitais.

Diniz (2001) reforça que a escola deve buscar a integração das "novas" tecnologias aos conteúdos da proposta curricular para promover uma aprendizagem mais significativa e contextualizada. Nesse ponto, a própria Base Nacional Comum Curricular (BNCC), recomenda 
a utilização das tecnologias digitais da informação e comunicação (TDIC), destacando-as como competência geral da educação básica.

Compreender, utilizar e criar tecnologias digitais de informação e comunicação de forma crítica, significativa, reflexiva e ética nas diversas práticas sociais (incluindo as escolares) para se comunicar, acessar e disseminar informações, produzir conhecimentos, resolver problemas e exercer protagonismo e autoria na vida pessoal e coletiva (BRASIL, 2018, p. 9).

No Ensino Fundamental I, os desafios enfrentados pelos professores são diversos, aqui destacamos as dificuldades dos alunos, principalmente em matemática, uma vez que essa disciplina requer atenção especial, pois segue carregando o estigma de componente curricular difícil, inacessível, campeão de reprovações, que ocasiona aversão em boa parte dos estudantes da educação básica (NEGRÃO, 2019).

Os entraves no aprendizado da matemática, em suma, são gerados por déficits no raciocínio lógico, dificuldades na leitura e interpretação de enunciados, carência nos conhecimentos básicos, como as quatro operações (adição, subtração, multiplicação e divisão), dentre outros; isto revela que a alfabetização matemática é um ponto de reflexão para o desenvolvimento de pesquisas e políticas públicas que contribuam na melhoria desse quadro.

Diante desse contexto, o objetivo do artigo é apresentar as contribuições do uso da plataforma Khan Academy nas aulas de Matemática, com alunos do $5^{\circ}$ ano, do Ensino Fundamental, de uma Escola Municipal, da Zona Leste, da cidade de Manaus (AM).

A escolha da Plataforma Khan Academy, nesta investigação, ocorreu por conter inúmeros exercícios interativos e videoaulas que oportunizam aprender em qualquer espaço, em conexão à internet, permitindo que os professores adotem novas maneiras pedagógicas, como o modelo do Ensino Híbrido ${ }^{4}$, esclarecendo dúvidas dos alunos, realizando atividades e aprofundando os assuntos de maneira interativa.

Assim, o estudo é um convite para a reflexão sobre o uso das tecnologias digitais de informação e comunicação no ensino de matemática, rompendo paradigmas e ampliando olhares humanísticos frente a uma disciplina tão importante para o desenvolvimento integral do ser humano.

\footnotetext{
${ }^{4}$ Horn e Staker (2015) definem ensino híbrido como um programa de educação formal no qual um aluno aprende, pelo menos em parte, por meio do ensino on-line - estudante tem algum controle sobre pelo menos um dos seguintes elementos: tempo, lugar, modo e/ou ritmo do estudo.
} 


\section{O USO DE TECNOLOGIAS DIGITAIS NO ENSINO DE MATEMÁTICA: PERSPECTIVAS TEÓRICAS E PRÁTICAS}

Estimular a criatividade e a resolução de problemas matemáticos no processo de ensino e aprendizagem tornou-se uma missão desafiadora para os professores do século XXI, porque vivem em um ambiente informatizado e digital. Portanto, a utilização de tecnologias se tornou algo imprescindível na educação contemporânea.

Para Lemos e Lévy (2010), as tecnologias são suportes digitalizados da informação e da comunicação que proporcionam rapidez e interesse mediante o rápido acesso entre o indivíduo, bem como a construção de novos conhecimentos, o que deve "[...] permitir-nos compartilhar nosso conhecimento e apontá-los uns para os outros" (LÉVY, 2010, p. 17).

Moran (2000) esclarece que na era da informação e da tecnologia, todos estamos reaprendendo a conhecer e a ensinar, a integrar o individual e o grupal, o humano e o tecnológico. Assim, é importante diversificar a forma de ministrar aulas e de ensinar/aprender, tanto nos cursos presenciais, como nos à distância. Corroboramos com Moran (2000) no que tange o processo de ensinar de forma lúdica ou gamificada, pois esta realidade educacional vem estimulando diversos professores a buscarem conhecimentos sobre a utilização das novas tecnologias, com uso de laptops e tablets em sala de aula, assim fazendo conhecimento de aplicativos e games que podem ser aproveitados no processo de ensino e aprendizagem.

No campo educacional, Perrenoud (2000, p. 137) afirma que:

As novas tecnologias podem reforçar a contribuição dos trabalhos pedagógicos e didáticos contemporâneos, pois permitem que sejam criadas situações de aprendizagem ricas, complexas, diversificadas, por meio de uma divisão de trabalho que não faz mais com que todo o investimento repouse sobre o professor, uma vez que tanto a informação quanto a dimensão interativa são assumidas pelos produtores dos instrumentos.

Em uma discussão mais próxima do ensino da matemática, Jahn e Allevato (2010, p. 146) corroboram ao dizer que:

A prática docente em matemática é, muitas vezes, somente teórica, desconsiderando aplicações em outras áreas do conhecimento, inclusive formas alternativas de ensino. No que se refere aos computadores e sua utilização para aprender matemática, há grande variedade de softwares de domínio público ou de baixo custo.

Um ensino estático e fragmentado ainda é sinônimo das aulas de matemática em muitas escolas em nosso país, por isso defendemos que o professor que ensina tal disciplina precisa estar munido de métodos e técnicas que o direcione em prol de uma prática docente mais efetiva 
e significativa para seus estudantes. Nesse viés, existe uma forte discussão sobre o uso de metodologias ativas, tema recorrente da Educação Básica ao Ensino Superior.

A metodologia ativa de gamificação tem se destacado na área da educação, principalmente por ser um método de fácil aplicação. Fardo (2013) afirma que esta metodologia constitui-se em uma atividade aplicável aos processos de ensino e aprendizagem nas escolas e em ambientes de aprendizagem, empregando os elementos dos jogos nesses processos, visando aumentar o envolvimento e dedicação dos alunos, assim como nos games.

A gamificação no processo de ensino e aprendizagem de Matemática tem o intuito de utilizar itens cibernéticos a fim de atrair o discente pela temática da disciplina. Na visão de Kapp (2012), os mecanismos baseados em jogos auxiliam o engajamento, a motivação e o interesse dos educandos, promovendo aprendizado e a resolução de problemas, despertando o raciocínio lógico do aluno e tornando as aulas mais divertidas, visto que "não é mistério para ninguém que o modelo habitual de ensino precisa passar por uma grande reformulação para conseguir conquistar a atenção de uma geração que nasceu conectada, os denominados nativos digitais" (SILVA; MORAIS; TIBURTINO, 2019, p. 77).

Kapp (2012) afirma também que escolas e professores devem buscar a transformação de suas salas de aula em ambientes mais ricos e criativos com os jogos digitais, envolvendo o ensino e a aprendizagem, para isso, torna-se necessário trabalhar em uma perspectiva pedagógica contemporânea, utilizando-se das tecnologias que compõe a vida dos estudantes do século XXI.

Nesse sentido, um ensino gamificado não ocupa o lugar das aulas tradicionais, aqui entendidas como aquelas aulas em que o docente utiliza apenas pincel e quadro branco; pelo contrário, o artigo tem o interesse em descrever possibilidades de uso das tecnologias, estas interpretadas como um recurso a mais para o professor que ensina matemática.

\section{O KHAN ACADEMY NAS AULAS DE MATEMÁTICA}

O Khan Academy é uma ferramenta de ensino eficaz que vem para auxiliar alunos e professores no ensino de matemática, bem como em várias áreas do conhecimento. A proposta da plataforma é oferecer educação gratuita em nível internacional para qualquer indivíduo (CORRÊA, 2016). 
A plataforma foi criada por Salma Khan, professor em Boston (EUA), com o intuito de auxiliar uma prima que possuía muitas dificuldades com a matemática, contudo, a parente residia em outra cidade. Logo, Khan precisou adaptar a ferramenta para "rodar" de modo online. O progresso observado fez com que a ferramenta se espalhasse no mundo todo, sendo hoje uma das mais utilizadas para fins de aprendizado (SENA, 2014).

No Brasil, a plataforma teve sua difusão e tradução em 2014, pela Fundação Lemann e, desde então, tem ajudado mais de 5 milhões de brasileiros a desenvolverem suas habilidades de matemática de maneira leve, gamificada e divertida (LEMANN, 2015).

Segundo Corrêa (2016), a plataforma Khan Academy é uma ferramenta gratuita que disponibiliza mais de dez mil vídeos, com explicações de matemática, ciências, economia e história, contendo mais de quarenta mil exercícios interativos. A plataforma funciona como um jogo que tem o propósito de medir o conhecimento do educando, colocando-o diante de desafios, pois a cada questão respondida corretamente, o aluno avança em "fases".

Dentre os principais aspectos positivos no uso da plataforma Khan Academy, está o controle que o professor tem das atividades desenvolvidas pelos seus alunos, indicadas pelo professor-tutor ao aluno em questão, ou atividades que o próprio aluno considerou interessante em realizar, mediante decisão autônoma (CORRÊA, 2016, p.14).

Corrêa (2016) chama atenção de que estudar de forma autônoma - como propõe a Plataforma Khan Academy - requer dos alunos comprometimento, disciplina e espírito colaborativo. Já o professor, tem o desafio de mediar o processo de ensino e aprendizagem de maneira criativa, dinâmica e motivadora, pois:

[...] uma prática pedagógica orientada por estratégias de games e game design requer, antes de tudo, um entendimento profundo desse universo por parte dos professores. Esse é atualmente um dos maiores (se não o maior) desafios do cenário educativo nacional: formar professores capazes de lidar com esse novo contexto cultural, permeado por tecnologias e recursos digitais. Além de saber interagir com as tecnologias, eles precisam estar preparados para conhecer a sua linguagem e utilizála nos ambientes de aprendizagem pelos quais são responsáveis (FARDO, 2013, p. $18)$.

Em síntese, as TDIC fazem parte da geração atual de crianças e adolescentes no mundo todo, portanto, ao professor compete o aprimoramento de sua competência tecnológica para fazer uso dessas ferramentas em prol de um ensino atrativo e diferenciado, uma vez que a literatura apresenta as potencialidades das TDIC na educação, evidenciando suas características principais, tais como a interatividade e o entretenimento. 
Em nossos estudo, o Khan Academy ganha destaque nas aulas de multiplicação do componente curricular de matemática, sendo uma opção de ferramenta para gamificação e engajamento dos estudantes do quinto ano do Ensino Fundamental.

\section{METODOLOGIA}

Do ponto de vista metodológico, este artigo visa apresentar as contribuições do uso da plataforma Khan Academy nas aulas de matemática, com alunos do Ensino Fundamental, de uma Escola Municipal, da Zona Leste, da cidade de Manaus (AM).

Para isso, realizamos uma pesquisa-ação ${ }^{5}$ interventiva, na qual organizamos uma sequência didática com atividades envolvendo a operação de multiplicação e o uso da plataforma Khan Academy, acompanhando a participação, as resoluções de problemas matemáticos de multiplicação (atividades) e o envolvimento dos alunos nas aulas. Os instrumentos de coleta de dados foram observações sistemáticas, conversas informais, registros no caderno de campo e filmagens.

A sequência didática foi desenvolvida com 26 alunos, entre 10 (dez) a 12 (doze) anos de idade, do $5^{\circ}$ ano do Ensino Fundamental, em um Telecentro (Laboratório de Informática). Os participantes selecionados possuíam dificuldades para resolver problemas envolvendo as operações básicas. Contudo, nesse relato, tratamos especificamente da operação de multiplicação.

Dessa maneira, a sequência didática foi organizada em 3 (três) momentos, em encontros realizados duas vezes por semana, em um período de 3 (três) meses.

No primeiro momento, organizamos uma reunião com os pais dos alunos a fim de explicar e apresentar a pesquisa que seria realizada com os estudantes. Na oportunidade, solicitamos as assinaturas nos Termos de Consentimento Livre e Esclarecido (TCLE). Os responsáveis dos alunos também receberam login e senha da plataforma Khan Academy para que seus filhos pudessem utilizá-la em suas respectivas casas.

No segundo momento, os alunos do $5^{\circ}$ ano foram cadastrados na plataforma Khan Academy, passando a usá-la duas vezes na semana no período de 50 minutos em horário regular,

\footnotetext{
5 Conforme afirma El Andaloussi (2004), essa modalidade de pesquisa propicia a redução das distâncias entre pesquisadores, tomadores de decisão e atores, não se tratando, portanto, de uma simples ação experimental a serviço da pesquisa e nem de uma ação para resolver exclusivamente um problema sem a investigação de suas causas e consequências. Esta pesquisa visa uma ação que, por sua vez, demandará novas pesquisas - uma interrelação para uma possível transformação social.
} 
na sala de Telecentro da instituição. Assim, os estudantes foram observados e acompanhados pela pesquisadora que tomou nota das dificuldades e progressos na aprendizagem da multiplicação de números simples e compostos.

No terceiro momento, realizamos atividades e problemas matemáticos de multiplicação, bem como conversas informais com os alunos, a fim de compor os resultados da pesquisa-ação.

\section{RESULTADOS E DISCUSSÃO}

A aplicação da sequência didática ocorreu primeiramente em sala de aula (Figura 1), de modo que propusemos a resolução de problemas envolvendo a multiplicação, para observar as dificuldades que os alunos enfrentavam para realizar tais atividades.

A fim de melhor esclarecer isto, convém expor que esse contato prévio é fundamental para entender o contexto em que os participantes da pesquisa se encontram, posto que a proposta do estudo era apresentar possibilidades do uso das TDIC para o ensino de matemática. Logo, entender o lugar cognitivo que os alunos estão é primordial para não defender uma metodologia com base apenas no estereótipo de que as tecnologias são as "salvadoras" da escola do século XXI.

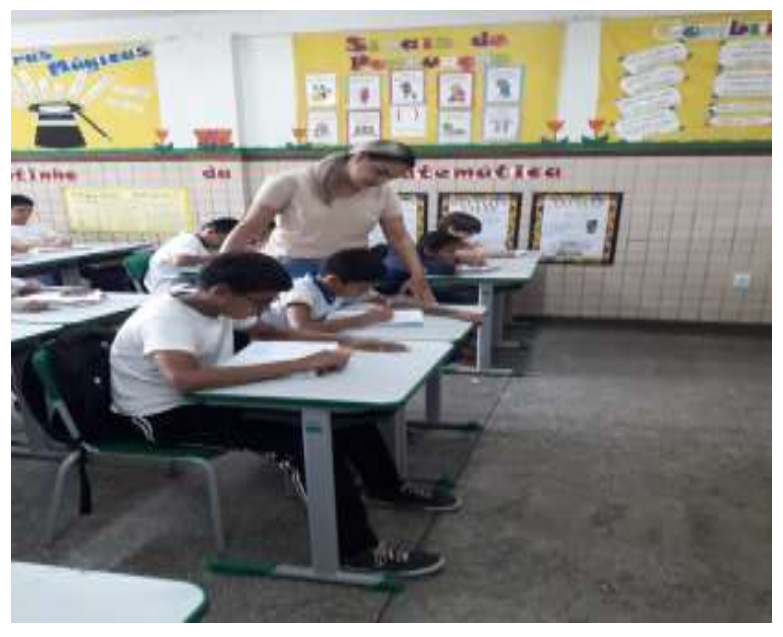

Figura 1 - Proposta de Atividades em sala Fonte: Vasconcelos, 2019.

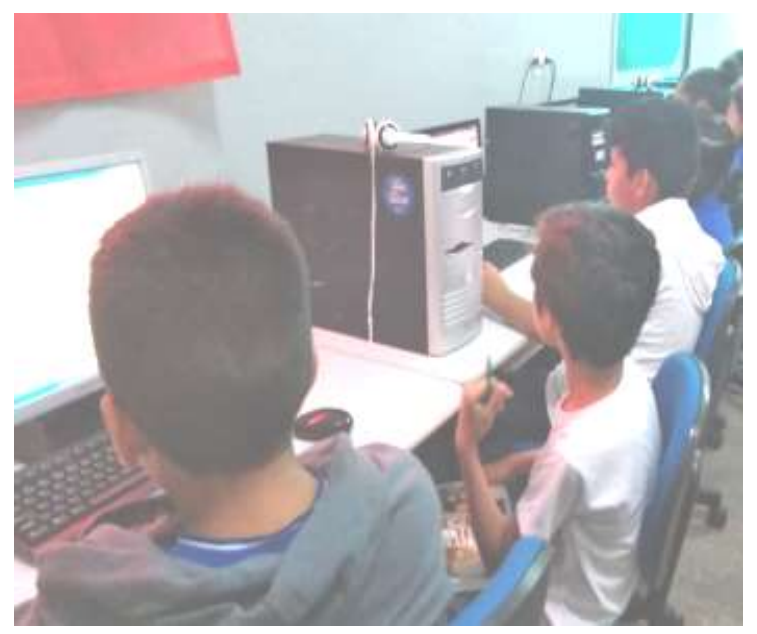

Figura 2 - Alunos no laboratório de informática Fonte: Vasconcelos, 2019.

As observações registradas em caderno de campo refletem um cenário de profunda dificuldade na resolução de cálculos e problemas de matemática, especialmente os de multiplicação, foco do estudo. As crianças participantes demonstravam insegurança, nervosismo, inquietações, além do sentimento de incapacidade, por vezes, utilizando de subterfúgios para sair da sala de aula, simplesmente para não responder as atividades propostas. 
Essa dura realidade se aproxima ao conceito de matemafobia de Santos e Cordeiro (2016), que resulta na aversão à matemática, sendo responsabilidade do docente viabilizar estratégia que contribuam para um olhar mais humanístico à matemática, referendando seu rigor científico. Diante disso, deve ele utilizar-se de estratégias pedagógicas que despontem de novas aprendizagens significativas e contextualizadas.

Pais (2002, p. 27) afirma que:

A contextualização do saber é uma das mais importantes noções pedagógicas que deve ocupar um lugar de maior destaque na análise da didática contemporânea. Trata-se de um conceito didático fundamental para a expansão do significado da educação escolar. $\mathrm{O}$ valor educacional de uma disciplina expande na medida em que o aluno compreende os vínculos do conteúdo estudado com um contexto compreensível por ele.

A partir das observações das dificuldades na resolução dos cálculos e problemas de multiplicação, foram sistematizados pequenos grupos para os encontros no laboratório de informática a fim de apresentar a plataforma Khan Academy para os alunos conhecerem novas formas de estudar matemática.

Devido ao pequeno porte do laboratório de informática (Figura 2) e o número ofertado de computadores não ser suficiente para atender a quantidade total de alunos, organizamos a turma em dois grupos. Por isso, enquanto 14 (quatorze) acessavam os computadores no laboratório de informática, os outros 12 (doze) estudavam em sala de aula.

No laboratório, os alunos acessavam o link "Fundamentos da Matemática" - em específico no conteúdo de multiplicação na plataforma Khan Academy, como mostra a Figura 3.

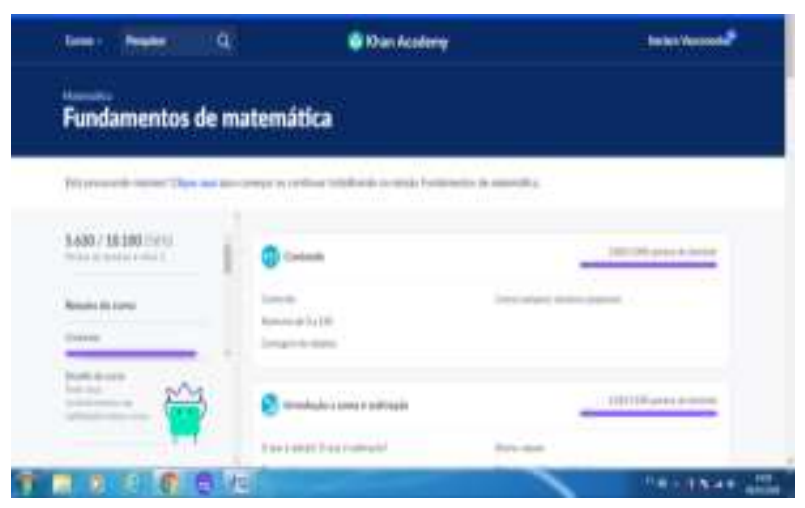

Figura 3 - Visualização da plataforma Fonte: Vasconcelos, 2019. 
Uma peculiaridade notada em nossas observações foi que alguns alunos, por não terem contato e acesso às tecnologias digitais e à internet, apresentaram dificuldades no manuseio da plataforma. Por isso, foi necessário que apresentássemos alguns recursos do computador, tais como: mouse, teclado, monitor, teclas de atalho, dentre outros.

Durante os encontros, percebemos o interesse dos estudantes para jogarem na plataforma e avançarem de fase junto ao seu avatar ${ }^{6}$.

Os resultados da pesquisa-ação apresentam que dos 26 (vinte e seis) alunos, tivemos uma média de 16 (dezesseis) alunos que obtiveram nota máxima nas atividades propostas nos encontros.

Por sua vez, a figura 4 apresenta os estudantes no pequeno laboratório de informática, mas também expressa o exercício autônomo dos alunos, estes que estavam conhecendo e aprendendo mais sobre matemática por meio da plataforma Khan Academy.

A figura 5 é a tela que expressa os acertos dos alunos, nela podemos notar os elementos de engajamento que fazem com que o jogador tenha interesse em continuar jogando, consequentemente aprendendo.

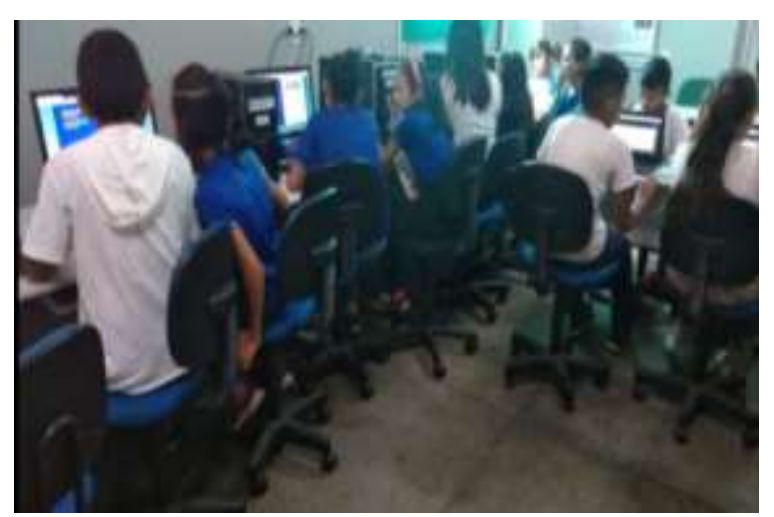

Figura 4 - Alunos no laboratório completando as atividades propostas.

Fonte: Vasconcelos, 2019.

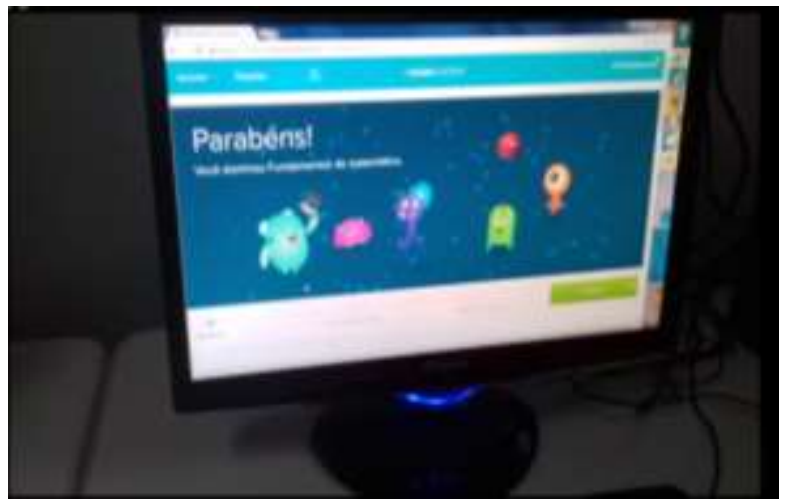

Figura 5 - Jogo Fundamentos da Matemática. Fonte: Vasconcelos, 2019.

Em conversa informal com a professora responsável da turma, foi informado que um dos estudantes apresentava desinteresse pelo estudo, falta de atenção, dificuldades em resolução matemática, altos índices de absenteísmo escolar e inquietabilidade. Para efeito de pesquisas futuras, durante o período de intervenção pedagógica, este aluno, em específico, passou a

\footnotetext{
${ }^{6}$ Uma figura virtual, interativa, usado como personificação de um jogador no mundo cibernético
} 
interagir mais com os colegas de classe, obtendo um melhor rendimento perante as atividades, zerando a quantidade de faltas durante os dias do componente curricular de matemática.

Em uma das gravações das aulas destacamos a fala daquele estudante que assegura a eficiência da plataforma.

Aluno X: Professora, eu já passei de fase, eu acessei mais que o meu colega! Estou fera!!! ${ }^{7}$

O relato do aluno nos mostra que o ensino de matemática, ao receber contribuições das TDIC, possibilita o desenvolvimento de competências e habilidades matemáticas, além da superação de déficits oriundos de uma má alfabetização matemática, permitindo também que o educando alcance um grau elevado de letramento matemático. Com efeito, observamos nisso melhora no rendimento escolar, autoestima e interesse pelos estudos.

Outro ponto em destaque nas observações sistemáticas é o senso de competitividade gerado na turma, de modo que eram constantes as frases "pulei de fase", "ganhei uma estrela", "zerei essa etapa", o que indiretamente proporcionava uma melhor aquisição e compreensão dos conteúdos ministrados na sala de aula, bem como a motivação para continuar aprendendo e desenvolvendo as atividades de multiplicação.

Nesse ínterim, a gamificação também permitiu avanços nos alunos que já eram mais aplicados, como é o caso da Aluna Y, que diferente do aluno anterior, era bastante dedicada, atenciosa; todavia realizava os cálculos com o auxílio dos $\operatorname{dedos}^{8}$. Durante o período da pesquisa, a aluna passou a realizar os cálculos de forma rápida e eficaz.

Aluna Y: Professora, tá muito fácil o nível, eu já tô encerrando fundamentos da matemática! Já não conto nos dedos! ${ }^{9}$

As falas dos alunos $\mathrm{X}$ e $\mathrm{Y}$ e as resoluções das atividades envolvendo a multiplicação demonstram que as atividades do Khan Academy geram interesse de avançar o nível do jogo, para isso é necessário estudar, prestar atenção nas atividades e orientações na sala de aula, portanto, sendo aqui um recurso a mais para contribuir com o trabalho do docente.

Com o uso do Khan Academy, a professora envolvida na pesquisa e a própria pesquisadora perceberam o avanço e o desempenho positivo dos alunos, e como a plataforma

\footnotetext{
${ }^{7}$ Gravação em áudio no celular.

${ }^{8}$ Registro da pesquisadora no caderno de campo.

${ }^{9}$ Gravação em áudio no celular.
} 
pode colaborar com o processo de ensino e aprendizagem da matemática, despertando motivação e interesse nos alunos.

Desta maneira, corroboramos com Corrêa (2016) quando este salienta que mediante a plataforma Khan Academy o aluno exerce o protagonismo, permitindo obter recompensas (mudança de nível) conforme realiza as atividades indicadas, o que propicia uma aprendizagem significativa e divertida.

\section{CONSIDERAÇÕES FINAIS}

O uso das TDIC é importante no processo de ensino e aprendizagem do século XXI, uma vez que contribuem na dinamização da sala de aula, permitindo a integração de novos saberes, muito desses, presentes em nosso cotidiano. Especialmente, no ensino de matemática que possui a fama de estático, tradicional e difícil, o uso das TDIC contribui na ressignificação de ideias e concepções que, por vezes, mais afastam do que acolhem os estudantes da educação básica.

No início da pesquisa-ação, com o uso da plataforma Khan Academy - por ser uma novidade aos alunos, notamos certa euforia para conhecer, brincar e utilizar os computadores. Uma resposta natural, posto que muitas escola dispõe do espaço do telecentro, pouco o utilizam, ou reduzem o uso a apenas projeção de filmes em dias comemorativos. O manuseio dos computadores pelos alunos também é um resultado expressivo, pois permitiu o exercício autônomo de direcionar sua própria aprendizagem, embora sempre supervisionado por uma professora/pesquisadora.

Dessa forma, observamos que o ambiente escolar se tornou muito mais aprazível e fomentador de experiências na área de matemática, posto que ao final da realização da sequência didática, os alunos demonstraram maior rendimento escolar no componente supracitado, obtendo índices maiores em suas notas. Obviamente que o intuito maior da experiência não era apenas quantitativo, mas enxertar ânimo e motivação para o aprendizado de matemática, uma vez que esta disciplina pode ser trabalhada de formas diversas, oportunizando saberes para a vida cotidiana do educando.

Ademais, no decorrer do desenvolvimento desta investigação, observamos a importância do professor como mediador do processo, ressignificando sua didática e inserindo em suas aulas o uso de tecnologias digitais. 
Sendo assim, apontamos a plataforma Khan Academy como um meio pedagógico eficaz - não desmerecendo os outros - para uso didático-metodológico dos professores, com intuito de contribuir no processo de ensino e aprendizagem - principalmente na componente curricular de matemática.

Por fim, consideramos que a experiência com a plataforma nos (e)leva a crer que as estratégias diferenciadas, metodologias ativas e contextualização do saber são caminhos que auxiliam o desenvolvimento de uma prática profissional mais efetiva, oportunizando um cenário educacional mais propenso ao aprendizado social, cognitivo e afetivo.

\section{REFERÊNCIAS}

BRASIL. Ministério da Educação. Base Nacional Comum Curricular: educação é a base. Brasília: MEC, 2018.

CORRÊA, P. M. H. A plataforma Khan Academy como auxílio ao ensino híbrido em Matemática: um relato de experiência. Dissertação de Mestrado Profissional - PROFMAT Rio Grande, 2016.

DINIZ, S. N. F. O uso das novas tecnologias em sala de aula. Dissertação (Mestrado em Engenharia da Produção). Universidade Federal de Santa Catarina, Florianópolis, 2001.

EL ANDALOUSSI, K. Pesquisas-ações: ciências, desenvolvimento, democracia. São Carlos: Edufscar, 2004.

FARDO, M. L. A gamificação como estratégia pedagógica: Estudo de elementos dos games aplicados em processos de ensino e aprendizagem. Dissertação (Mestrado). Universidade de Caxias do Sul, Curso de Pós-Graduação em Educação, Caxias do Sul, 2013.

HORN, M. B; STAKER, H. Blended: usando a inovação disruptiva para aprimorar a educação [recurso eletrônico]. Porto Alegre: Penso, 2015.

JAHN, A. P; ALLEVATO, N. S. G. Tecnologias e educação matemática: ensino, aprendizagem e formação de professores. Recife: SEBEM, 2010.

KAPP, K. The gamification of learning and instruction: game-based methods and strategies for training and education. San Francisco: Pfeiffer, 2012.

LEMANN, F. Khan Academy - O maior site de matemática do mundo. 2015. Acesso em 15 jan 2020. Disponível em: < https://fundacaolemann.org.br/>

LEMOS, A; LÉVY, P. O Futuro da Internet: Em direção a uma ciberdemocracia planetária. São Paulo: Paulus, 2010. 
LÉVY, P. A. A inteligência coletiva: Por uma antropologia do ciberespaço. São Paulo: Loyola, 2010.

MORAN, J. Ensino e aprendizagem inovadores com tecnologias audiovisuais e telemáticas. In: MORAN, J; MASETTO, M; BEHRENS, M. Novas tecnologias e mediação pedagógica. Campinas, SP: Papirus, 2000.

NEGRÃO, F. C. Ressignificando o ensino de matemática: uma experiência com professores em formação. In: BARBOZA, P. L. (Org.). Pesquisas em Educação Matemática. Jundiaí: Paco Editorial, 2019.

PAIS, L. C. Didática da matemática: uma análise da influência francesa. 2. ed. Belo Horizonte: Autêntica, 2002.

PERRENOUD, P. 10 novas competências para ensinar. Porto Alegre: Artmed, 2000.

PRENSKY, M. Digital Natives Digital Immigrants. On the Horizon, MCB University Press, v. 9, n. 5, p. 1-6, out. 2001.

SENA, Í. V. de. O. Aprendendo matemática através do Khan Academy. Monografia (Especialização em Fundamentos da Educação: práticas pedagógicas interdisciplinares). Universidade Estadual da Paraíba, Paraíba, 2014.

SILVA, A. M. S; MORAIS, C. F. A; TIBURTINO, N. A. C. T. Aprendizagem matemática e o ensino híbrido: possibilidades de personalização nos anos iniciais do ensino fundamental. REAMEC - Rede Amazônica de Educação em Ciências e Matemática, [ $S$. l.], v. 7, n. 3, p. 74-91, 2019.

Submetido em: 12 de junho de 2020.

Aprovado em: 28 de julho de 2020. 